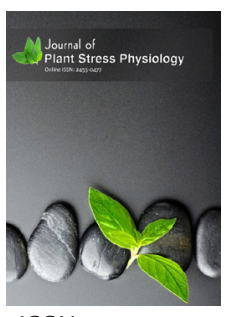

ISSN: $2455^{-0} 0477$

\title{
Attempt of Costus arbuscular mycorrhizal inoculants association with leguminous foliage whey on chlorophyll of sunflower (Helianthus annus L.) plants
}

\author{
Jadhav Rajesh K*, Lodhi Anil \\ Research Laboratory, Department of Botany, D.G. Ruparel College, Mahim, University of Mumbai, Mumbai, India
}

\begin{abstract}
Reporters founded that mycorrhizal association in plant kingdom improves the plant growth. The present attempt has been on the use of Mycorrhiza for Helianthus growth in stress condition of the adverse red soil of konkan region, India and other climatic factors. Earlier reporters for the purpose to avoid chemical fertilisers, founded that Deproteinised juice (DPJ) or foliage whey induces appropriate plant growth and enhance soil fertility. During present investigation, mycorrhiza from Costus sp application to soil of potted sunflower plants influence was compared with organic DPJ addition obtained from fenugreek foliage during the process of green crop fractionation (GCF) technique. This whey is randomly disposed during this technology of leaf protein preparation, so appropriate use of it is advised. Whether the mycorrhiza and DPJ combination treatment were feasible for seed germination and the seedling growth of the Helianthus plant, it was analysed and compared with control. Studies were experimented on the effect of mycorrhiza treated alone and DPJ treated alone whether improves the plant growth. DPJ if added with mycorrhiza in soil, showed significant rate of germination. In earlier research it was elucidated that the DPJ contains phytohormones auxins, gibberellins and cytokinins in unknown quantity which boosts the plant growth comparative to mycorrhizal influence. The chlorophyll content of the DPJ treated plants enhanced as compared with control while the content showed no significant difference with mycorrhiza.
\end{abstract}

*Corresponding Author: Jadhav Rajesh K

E mail: rajesh.jadhav @ruparel.edu

\section{INTRODUCTION}

By the process of green crop fractionation (GCF), the LPC (Leaf protein concentrate) obtained use as a protein and vitamin A supplement in human and animal nutrition is well recommended while the DPJ is considered as a byproduct of this process [1]. To make the process more efficient and economical, the DPJ has to be used in a proper way as it is disposed randomly and majority of nutrients gets shifted to DPJ from juice after heating.

In earlier studies, the Lucerne DPJ influence was envisaged on cowpea crop compared with urea and superhosphate fertilisers. They found the significant enhancement in protein content and dry biomass of [(Vigna unguiculata L.) walp] crop as compared with urea and superphosphate chemical fertilisers. Soil application of DPJ performed promising results in achieving the proper expression of nitrate reductase. Fungi like Aspergillus niger was also cultured successfully on DPJ of plants like pea vines [2]. Ghewande and Deshpande [3] cultivated 5 fungi including Aspergillus on the DPJ expressed during fractionation of hybrid Napier grass. After the fungal growth when the culture filtrates were collected, they were used for the production of secondary metabolites.

In earlier studies, when the DPJ is used as the biofertiliser and used as the soil conditioner for plants, there was appreciable amount of the growth of rhizospheremicroflora due to it [4]. DPJ found effecting appropriate growth of Rhizobium bacteria for nitrogen fixation and enhancing number and size of root nodulation in leguminous plants and significant in enhancing the organic acids production by fungi if grown on it [5].

Soil inhabitants Arbuscular mycorrhizal fungi (AMF) form associations with the vast majority of plant species. They play

Copyright: $\odot$ The authors. This article is open access and licensed under the terms of the Creative Commons Attribution License (http://creativecommons.org/licenses/by/4.0/) which permits unrestricted, use, distribution and reproduction in any medium, or format for any purpose, even commercially provided the work is properly cited. Attribution - You must give appropriate credit, provide a link to the license, and indicate if changes were made. 
key roles in soil structure, biogeochemical cycles etc, help plants to acquire nutrients in exchange for carbohydrates and protect them from stresses [6,7]. For instance, an increase in plant shoot biomass as well as $\mathrm{Zn}$ and $\mathrm{P}$ content in $\mathrm{AMF}$ - colonized lucerne species grown in a hydrocarbon - polluted substrate as compared to non - colonized plants [8].

In the present experiment, the DPJ or whey is added with the mycorrhiza. Mycorrhiza can easily utilize the nutrients available in DPJ for its development. In return it provides its nourishment to the plants and becomes fit to survive. Reporters revealed that AM Fungus Sclerocystis dussii was most efficient to medicinal shrub Costus speciosus. There was significant enhancement in plant height, leaf length and number, total chlorophyll content and increased stem tubers length, diameter and phosphorus content as compared to control uninoculated plants. However, this enhanced growth response was influenced by other promising AMF species [9]. When phosphorus content present in the soil, plant growth with the effect of mycorrhiza varies $[10,11,12]$.

During present investigation, it was predicted that, there will be optimal result when DPJ is combined with Mycorrhiza. As DPJ also consists of nutrients, vitamins, phytohormones, carbohydrates, amino acids etc., hence the good efficacy of mycorrhiza with addition of DPJ as substrate serving for seedling growth than that of the controlled potted plants was expected. After plant growth, microscopic study of mycorrhizal association with roots, whether DPJ plus mycorrhiza or mycorrhiza alone favours more symbiotic association was studied. The comparative study of root sections and chlorophyll content of leaves from all pots were expected to show favourable results when DPJ obtained from leguminous plant species fenugreek was served.

\section{MATERIALS AND METHODS}

\section{Technique of leafy deproteinised whey}

In view of using plant nutrients more efficiently, the process of green crop Fractionation (GCF) technology was advocated. During GCF, fresh green leaves were macerated and subsequently pressed. The leaf juice released due to the pressing was then heated to $95^{\circ} \mathrm{c}$, as a result of which, proteins in juice, coagulate to form a curd referred to as leaf protein concentrate (LPC). The LPC was isolated from remaining portion of leaf juice, called as deproteinised juice (DPJ) or "whey", by filtration through cotton cloth.

\section{Treatment of whey and mycorrhiza}

The mycorrhizal roots of Costus were collected from Tungareshwar Vasai forest, Palghar, India. Use of the mycorrhiza from Costus was taken into consideration for the effect of germination and growth of sunflower (Helianthus annus L) plants. Another medium for comparison as a fertiliser was also prepared from the deproteinised leafy extract from leguminous crop fenugreek (Trigonella foenicum graceum L). Four pots and the three replicates were arranged for the research.
In pot 1 , seeds were sown for germination by the influence of mycorrhiza by addition of DPJ i.e. mixed in soil seperately. In pot 2, there was only Mycoorrhiza added in the soil for seed germination. In pot 3, only DPJ was added as the fertiliser for seed germination and crop growth.In pot 4 , for comparison, this pot was control, having untreated soil to germinate the seeds. In pot no. $3^{\text {rd }}$ and $4^{\text {th }}$, there was no source of mycorrhiza, i.e. DPJ treated pot and untreated pot of control.

The parameters studied were of the measurement of lengths and number of leaves of the plants of all the treated and untreated pots. Anatomical studies of mycorrrhizal association of the DPJ and mycorrhiza treated plants were compared to the control. Mycoorrhiza also mixed with DPJ and treated to the plants. Chlorophyll content by Arnons methods was estimated in the seedlings.

\section{Extraction of Spores}

The spores were isolated from the soil samples by wet-sieving and decanting technique [13].

\section{Spore Density Calculation}

Density of spores in each soil sample was calculated by following standard method [14]. The observed spores were micro photographed at two magnifications $(4 \mathrm{x}, 10 \mathrm{x})$.

\section{Method and identification of root arbuscular mycorrhizae slide preparation of the sunflower plants}

Collected roots which were to be investigated for infection by Mycorrhizal fungi were first washed thoroughly with water. The roots were then treated with $10 \% \mathrm{KOH}$ for half an hour at $90^{\circ} \mathrm{C}$ in a water bath. These roots were then transferred to a petriplate and washed with water. The roots were then kept in $1 \% \mathrm{HCl}$ for $10-15$ minutes at room temperature. The roots were then washed again after treatment with $\mathrm{HCl}$, and transferred into Cotton blue Stain. The roots were kept in stain overnight. The next day, the roots were observed under compound microscope. Permanent slides were prepared after observing slides.

\section{Detection of Mycorrhizal Spores from Soil of cultivated sunflower plants in the pot}

10 gms of soil added to $1000 \mathrm{ml}$ of Distilled water. The soil was mixed well in water and kept overnight. Therefore soil settles down and the spores of Mycorrhiza remains on the above surface of water. This water was passed through sieves of different pore sizes. The spores collected in the sieve were transferred into a beaker by passing water through the sieve. This water was then filtered through Whatmann filter paper and the mycorrhizal spores were collected in the filter paper. The whatmann filter paper was then placed in a petriplate and then the spores in the filter paper were observed under a microscope. The Mycorrhizal spores on the filter paper were then transferred on a slide with the help of a needle and permanent slides were prepared. 


\section{Arnons method of chlorophyll estimation}

$100 \mathrm{mg}$ of leaf was taken and crushed in acetone by adding Magnesium carbonate to form the supernatant by centrifuge. Supernatant was used to assess the spectrophotometric optical density on 663 and $645 \mathrm{~nm}$ wavelengths for chlorophyll A and B.

\section{RESULTS AND DISCUSSION}

Mycorrhiza favours the plant growth naturally. The fungal association in mycorrhiza greatly increased the surface area of the roots and thus absorption of water and minerals also from DPJ. The artificially prepared natural biofertilizer called DPJ is utilised to favour the plant growth for comparison. DPJ also found enhanced secretion of the organic acids in fungi [15]. In earlier research, it was found that the rate of germination of sunflower by the influence of Eicchornia, Colocasia and radish DPJ was adverse. There was lesser number of sunflower seeds germinated by application of these plants, from which the DPJ was obtained. It was Ipomea batata from convolvulaceae, which was unable to reproduce vegetatively when underground stem was cultivated and the treatment of DPJ was given before the branch emergence. In case of Tagetes also, when the DPJ was mixed in soil before the germination, the seeds germinated late as compared with control. But the marigold plants gave more number of yellow flowers phenotypicaly by the influence of DPJ. Figure 1 (a,b,c,d) illustrates that the fenugreek DPJ alone reduced the rate of germination showed in pot 2. Table 1 illustrates DPJ when added to mycorrhiza, there was no obstruction, but it was found increase in seed germination as showed in pot C. Pot D shows the mycorrhizal effect on seed germination which was more as compared with control of pot A.

In pot B of the fenugreek DPJ treated seeds of sunflower, the number of seeds germinated were 7 which was lesser than that of the control i.e untreated seeds of sunflower pot no. 4. In pot A of mycorrhiza, 17 plants were germinated. Comparatively with DPJ, mycorhhiza treated seedlings showed more mean length. But in pot A, when the DPJ was added to mycorrhiza the total number of plants germinated were 19. Therefore the result was significant when DPJ was added to the mycorrhiza for seed germination in the soil, that the number of seeds germinated were more as compared with the treatment of mycorrhiza alone. While on the other hand, the result showed the rate of germination decreased when the alone DPJ was added to the soil as it is sticky in nature. Earlier workers reported that, the DPJ treated plants comparatively resulted better when the application given after the seedlings attained the height of 7 $\mathrm{cms}$ in cowpea, pea and various gramineae members. Therefore it indicates that application of DPJ to the seeds should be given after the emergence of the seedlings or can be along with mycorrhiza. Figure 2 illustrates the graphical presentation of the seed germination by the influence of mycorhiza and when DPJ is added to mycorrhiza. Figure 2 indicates graphically that, the mycorrhiza if substituted in DPJ, it induces rate of seed germination as compared with control .

Growth of the sunflower seedlings depicted in figure 1, a, b, c and D. After the observation in the slides, there was the presence of the mycorrhizal spores depicted in figure $3, \mathrm{a}, \mathrm{b}$ and $\mathrm{c}$.

When there was no application of mycorrhiza given in pot of control and DPJ, despite there found presence of other endophytic fungi illustrated in figure 5. Mycorhizal hyphae as well as spores were slightly more as compared with control figure $4 \mathrm{a}$ and DPJ of figure $5 \mathrm{~b}$. Figure $5 \mathrm{c}$ and d illustrates the presence of arbuscles in few tissues of the root sections as the treatments were of DPJ added in mycorrhiza and mycorrhiza treated alone. Collins [1] report suggests that the $1 \mathrm{~cm}$ application rate of whey reduced yield and in some cases killed a portion of the plants. Walgenbach et al [16] indicate that when higher rates of deproteinised alfalfa juice (DPAJ) were applied some damage or death of plants, particularly with alfalfa and corn was occured. The source of DPJ was not the major factor in alfalfa plant damage, but the rate of application was a major factor. Saponins did not appear to be a damaging agent.

Vesicular-arbuscular mycorrhiza (VAM) is formed by the symbiotic association between certain phycomycetous fungi and angiosperm roots. The fungus colonizes the root cortex forming a mycelial network and characteristic vesicles (bladderlike structures) and arbuscules (branched finger-like hyphae). Figure 5 indictaes the presence of vesicles in slide a and b, with mycorrhiza treated alone. The result of DPJ in addition to mycorrhiza induced the growth of the vesicles. These vesicles are important for the absorption of nutrients by the roots. DPJ added with mycorrhiza induced more hyphal growth as compared with the mycorrhiza treated alone as seen in figure 6 , a and b. Arbuscules occurred in pairs in adjacent cortical cells

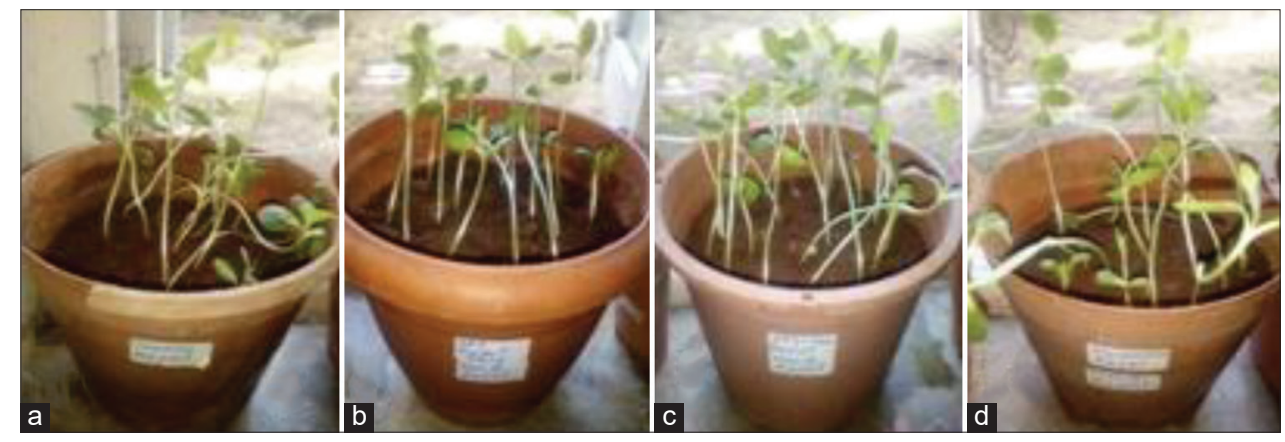

Figure 1 : Photographical illustration of the sunflower plants growing in the pots after the treatment (a) Control (b) DPJ (c) Mycorrhiza added with DPJ (d) Only Mycorrhiza 
arising from a single, radial intercellular hypha. These "paired" arbuscules often appeared to be at different developmental stages as seen in figures $6 \mathrm{a}$ and $\mathrm{b}[17,18]$. Logistic regression and measurement of surface area indicated that there was a delay in initiation of the second arbuscule.

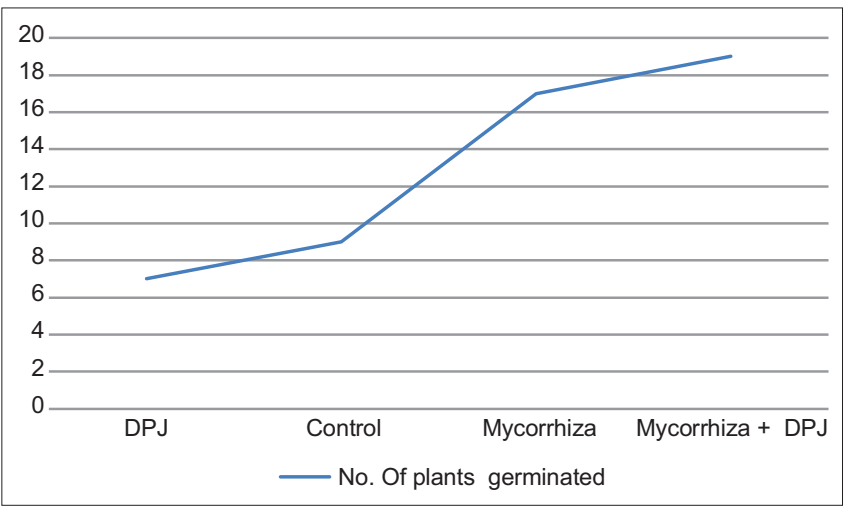

Figure 2 : Graphical illustration of the number of sunflower seeds germinated by the influence of Costus mycorrhiza and Fenugreek DPJ as compared with control

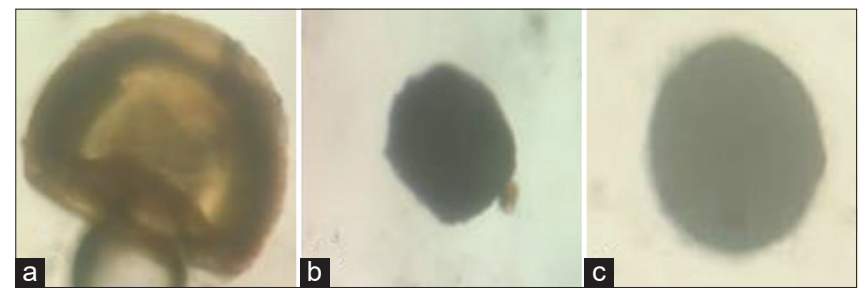

Figure 3 : Illustration of spores found in the soil in pots treated by (a) DPJ, (b) mycorrhiza alone and (c) addition of mycorrhiza with DPJ as compared with control

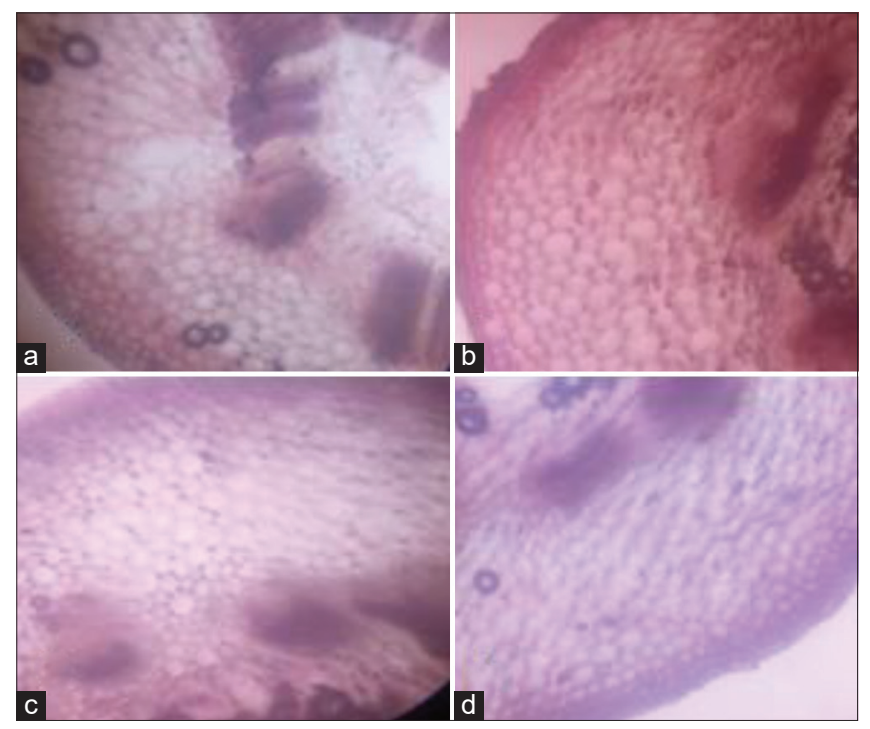

Figure 4 : Sections of the sunflower plant roots after growth by the influence of myorhhiza alone and mycorrhiza added in the DPJ. (a) is Control (without any treatment) (b) is soil is added with DPJ (c) Mycorrhiza added with DPJ in soil and (d) Only Mycorrhiza mixed in soil before seedling growth
DPJ induced the chlorophyll content of sunflower plants as compared with control as shown in table 2. When mycorrhiza added in DPJ there was increase in its chlorophyll content as compared with control. The Costus mycorrhizal association to roots to sunflower plants was found beneficial to raise the chlorophyll content which indicates the appreciable process of photosynthesis. The result indicates that leguminous fenugreek DPJ has the effficacy in inducing the chlorophyll content in the sunflower plants. The chlorophyll results tends to show that mycorrhiza alone is beneficial to treat for chlorophyll enhancement than that of getting the DPJ added in it [19].

Illustration of the significant difference in control and DPJ as well as mycorrhizal influence shown in figure 7 . There is no significant variation among treatment influence of DPJ and Mycorrhiza, only slight variation was found shown in figure 7.

The table 3 indicates that when the mycorrhiza alone was applied to the soil without DPJ before germination of sunflower seeds in the pots in triplicates, there was enhancement of the hyphal ramification. There were also the presence of coiled hyphae found in the soil. Mycorrhiza also influenced to form vesicles. There were presence of nearly 8 vesicles. The presence of arbuscles were totally three. The mycorrhiza were also in the reproductive stage to show the presence of spores. There were also the presence of other fungal endophytes in less quantity. Therefore the table 3 shows the percentage of mycorrhizal association by mycorrhiza application in the soil was $36 \%$. The sunflower crop thrieved well due to the application of alone mycorrhiza without DPJ.

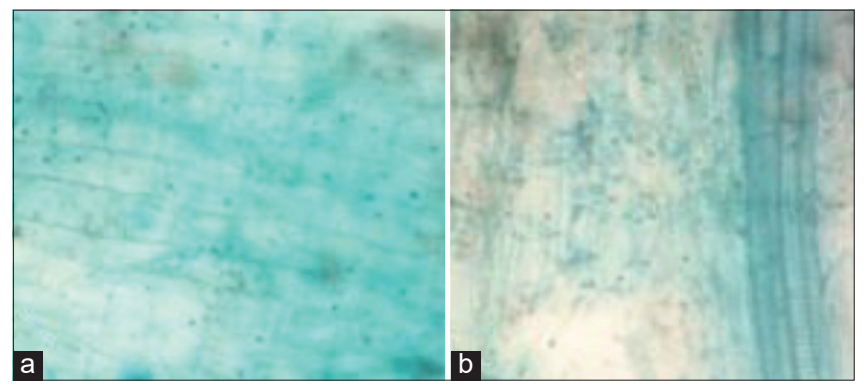

Figure $5:$ L. S. of roots of sunflower plants after the treatment of mycorrhiza in the soil.Sunflower root cortical cells containing mycorhizal arbuscles to the hyphae. Paired arbuscles are seen in (a) and (b) in pot treated by mycorrhiza singly

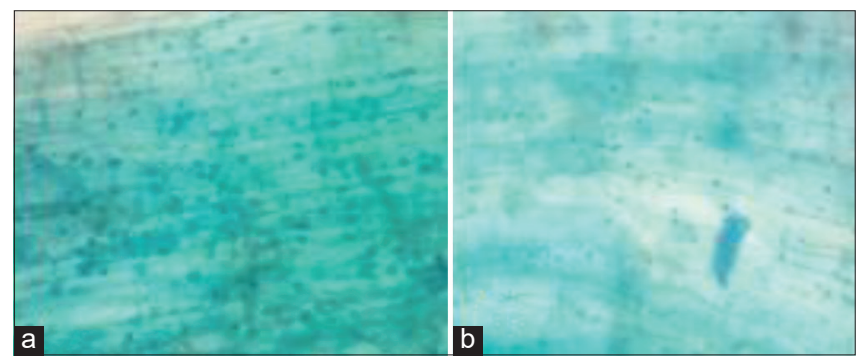

Figure 6 : Effect of DPJ with addition of mycorrhiza on arbuscular mycorrhizal association in roots of sunflower. (a) and (b) showing vesicles of mycorrhizal hyphae and paired arbuscles are also depicted 


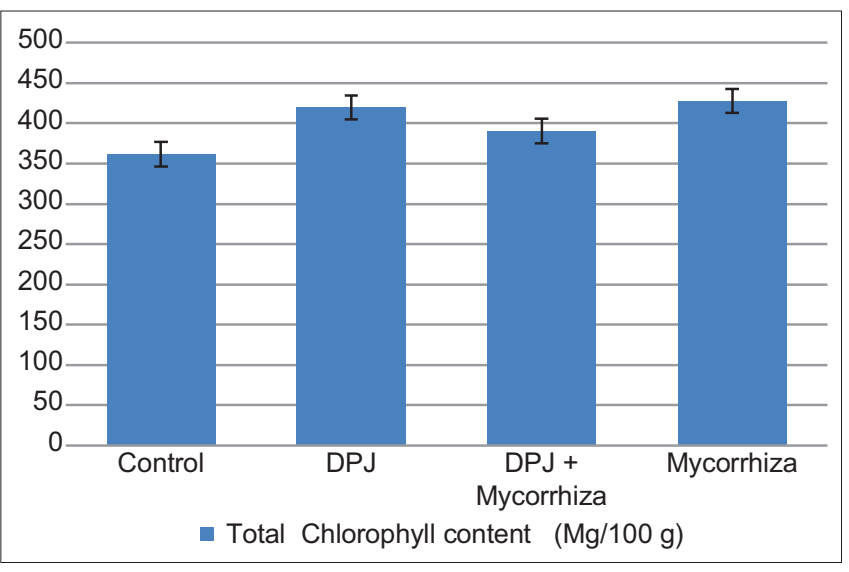

Figure 7 : Graphical presentation of the total chlorophyll content of sunflower plants treated by Fenugreek DPJ and Costus mycorrhiza with standard deviation error bars

Table 1: Effect of mycorrhiza and DPJ on the seed germination and seedling growth.

\begin{tabular}{|c|c|c|}
\hline Variables & Treatment & No. of sunflower seeds germinated \\
\hline 1 & DPJ & 7 \\
\hline 2 & Control & 9 \\
\hline 3 & Mycorrhiza & 17 \\
\hline 4 & DPJ \& Mycorrhiza & 19 \\
\hline
\end{tabular}

Table 2: Estimation of chlorophyll content in extract by Arnons method in Mycorhizal and DPJ treated potted sunflower plants in replicates

\begin{tabular}{llccc}
\hline $\begin{array}{l}\text { Slide } \\
\text { No. }\end{array}$ & Treatment & $\begin{array}{c}\text { Chlorophyll A } \\
(\mu \mathrm{g} / \mathrm{ml})\end{array}$ & $\begin{array}{c}\text { Chlorophyll B } \\
(\mu \mathrm{g} / \mathrm{ml})\end{array}$ & $\begin{array}{c}\text { Total Chlorophyll } \\
(\mathrm{mg} / 100 \mathrm{~g})\end{array}$ \\
\hline 1 & Control & 23.815 & 12.366 & 361.81 \\
2 & DPJ & 27.997 & 13.970 & 419.67 \\
3 & DPJ \& & 26.017 & 13.024 & 390.41 \\
& Mycorrhiza & & & \\
4 & Mycorrhiza & 28.744 & 14.035 & 427.79 \\
\multicolumn{7}{l}{ Variance 903.2} & & & \\
\hline
\end{tabular}

On the other hand, in table 4, it indicates that when the mycorrhizal application given to the soil before the seed germination of sunflower with the addition of deproteinised leaf juice (DPJ), there was the enhancement in the percentage of the mycorrhizal association, i.e $46.6 \%$ as compared with alone mycorrhizal treatment i.e $36 \%$. Mycorrhiza added with DPJ induced the enhancement of the vesicles comparatively with alone mycorrhizal treatment, shown in figure 4 . Also there were presence of more spores. This indicates the DPJ responsible to induce more reproduction in the mycorrhiza as compared with mycorrhiza when alone was treated in another pot. There were absence of other endophytic fungi positively. The results shown in figure 5. In earlier studies DPJ when utilized to grow fungi, it induced growth as compared with other substrates and secreted the enzymes xylanases and pectinases [20]. When DPJ treated to seeds by soaking to get imbibed before germination, it found protein and phytohormone induction to secrete enzyme amylases for optimum rate of germination [21,22].
Table 3: Percentage of fungal colonies of mycorrhiza by the influence of mycorrhizal inoculation in the soil of sunflower crop for growth.

\begin{tabular}{|c|c|c|c|c|c|}
\hline Slide No. & $\begin{array}{l}\text { Hyphae } \\
\text { types }\end{array}$ & Vesicles & Arbuscles & Spores & Percentage \\
\hline 1 & Hyphae & 12 & 3 & 2 & \\
\hline 2 & Coiled & 8 combined vesicles & 0 & 3 & \\
\hline 3 & Hyphae & & & & \\
\hline 4 & Total 6 & 20 & 3 & 3 & 36 \\
\hline
\end{tabular}

Table 4 :Percentage of fungal colonies of mycorrhiza by the influence of mycorrhizal inoculation in the soil of sunflower crop for growth with addition of leguminous fenugreek foliage DPJ.

\begin{tabular}{lcccc}
\hline Slide no & Hyphae & Vesicles & Spores & Percentage \\
\hline 1 & 2 & 19 & 9 & 46.6 \\
\hline
\end{tabular}

\section{CONCLUSION}

Hence leguminous fenugreek DPJ when added to mycorrhiza, it favours the rate of seed germination of non leguminous crop of sunflower, as it contains plant growth regulators IAA, GA and cytokinins at unknown quantity. Costus mycorrhiza found matching to get associated with the DPJ in increasing the availability of nutrients to the roots. There was good mycorhizal association within roots of sunflower and the Costus mycorrhiza. Besides increasing the overall absorptive surface, they also participated in solubilisation and mobilization of nutrients in the soil as well as from DPJ source. Therefore the results reveals that, in absence of mycorrhiza, DPJ found good chlorophyll content booster in sunflower plants to induce appreciable process of photosynthesis as compared with control. DPJ added in mycorrhiza induced the growth of vesicles so as to absorb more nutrients by the roots for the purpose of growth.

Therefore it is concluded that when the application of DPJ is given by the addition of mycorrhiza, the crop of the sunflower thrieved well as compared with the mycorrhizal treatment given alone to the sunflower plants before the germination of the seeds despite adverse use of the soil causing stress.

\section{ACKNOWLEDGEMENTS}

The authors are thankful to Ruparel College, affiliated to University of Mumbai authorities to provide laboratory facilities. Authors are grateful to Professor A.M. Mungikar, Ex. Head of Botany Department, Dr. Babasaheb Ambedkar Marathwada University, Aurangabad, India who was responsible to inspire ideas of the research.

\section{REFERENCES}

1 Collins M. In Recent Advances in Leaf Protein Research, Proceedings of the $2^{\text {nd }}$ International Conference on Leaf Protein Research, I. Tasaki (ed.), Nagoya and Kyoto, Japan. 1985: 149-151.

2. Reddy GU, Deshmukh VR, Joshi RN, Kayamaf R. Utilization Of Alfalfa (Mediacago sativa L.) Whey as a Fertilizer in Irrigation. J. Japan.Grassl. Sci., 1987; 33 (1): 32-37. 
3. Ghewande, MP, Deshpande, KB. Cellulolytic enzymes of Helminthosporium appatarnae. Indian Journal of Microbiology. 1975; 15: 33.

4. Doiphode DA, Mungikar AM. Rhizosphere mycoflora under the influence Of deproteinised leaf juice of lucerne. Sustainable Environmental Management. (Dr. Jayshree Deshpande Festschrift Volume by L.V. Gangavane and V. C. Khillare, published by Daya Publishing House) 2007; 75-88.

5. Chanda S, Matai S, Chakrabarti S. Deproteinized leaf juice as a medium for growth of Rhizobium. Indian Journal of Experimental Biology. 1987; 25 (8): 573-575.

6. Rillig, MC. Arbuscular mycorrhizae, glomalin, and soil aggregation. Can. J. Soil Sci. 2004; 84: 355-363.

7. Simard, SW, Austin ME. "The role of mycorrhizas in forest soil stability with climate change," in Climate Change and Variability, ed. S. Simard (Rijeka: In Tech Open), 2010; 275-301.

8. Cabello MN. Effectiveness of indigenous arbuscular mycorrhizal fungi (AMF) isolated from hydrocarbon polluted soils. Basic Microbiol. 1999; 39 (2): 89-95.

9. Kavatagi P, Lakshman HC. Screening of Potential Arbuscular Mycorrhizal Fungal Isolates for Costus speciosus, a Medicinal Plant in Unsterile Soil. Nature, Environment and Pollution Technology, An International Quarterly Scientific Journal, 2009; 8 (4): 673-676.

10. Ronsheim M. The Effect of Mycorrhizae on Plant Growth and Reproduction Varies with Soil Phosphorus and Developmental Stage. American Midland Naturalist. 2012; 167 (1): 28-39

11. Sari N, Ortas I, Yetisir H. Effect of mycorrhizae inoculation on plant growth, yield, and phosphorus uptake in garlic under field conditions. Communications in Soil Science and Plant Analysis. 2007; 33 (13-14): 2189- 2201.

12. Apolino J, Ricardo A, Juliana S, Jordan C, Fabíola G, Cosme J, Luiz E, Júlio G. Soil chemical properties and growth of sunflower (Helianthus annuus L.) as affected by the application of organic fertilizers and inoculation with arbuscular mycorrhizal fungi.
Microbiological Research. 2014; 169 (4): 294-300.

13. Gerdemann, JW, Nicolson, TH. Spores of Mycorrhizal Endogone Species Extracted From Soil by Wet Sieving and Decanting. Transactions of the British Mycological Society, 1963; 46 (2): 235-244.

14. Stahl, P, Christensen M. Mycorrhizal Fungi Associated with Bouteloua and Agropyron in Wyoming Sagebrush- Grasslands. Mycologia, 1982; 74 (6): 877-885.

15. Jadhav Rajesh K., Mulla M. Screening Of Organic Acids Production By Fungi Grown On Extracts From various Leaves After Protein Isolation In Vitro: The Novel Industrial Approach. International Journal Of Pharmacy And Pharmaceutical Research. 2018; 13 (4); 266-276.

16. Walgenbach RP, Smith D., Ream HW. Agron. J. 1977; 69: 690-694

17. Dickson S, Schweiger P, Smith FA, Söderström B, Smith S. Paired arbuscules in the Arum-type arbuscular mycorrhizal symbiosis with Linum usitatissimum Canadian Journal of Botany, 2003; 81 (5): 457-463.

18. Sang Joon Kim, Ju- Kyeong Eo, Eun- Hwa Lee, Hyeok Park, Ahn- Heum Effects of Arbuscular Mycorrhizal Fungi and Soil conditions on Crop plant growth. Eom Mycobiology. 2017; 45 (1): 20-24.

19. Jadhav RK, Kadam R, Joshi D. Physiology of Gramineae crops by deproteinised foliage extract and its 11. influence on photosynthetic chemistry. The Journal of Phytochemistry. 2019; 110: 149-163.

20. Jadhav Rajesh K, Fernandes Solomon S. Induction of xylanase and pectinase enzymes of Aspergillus derived from Mentha deproteinised leafy broth. International Journal of Botany Studies. 2019; 4 (6): 134-140

21. Jadhav RK. Gibberellin Induced $\alpha$-amylase and Protein Optimization in the Seedlings by the Influence of Deproteinised Leafy Whey from Selected Crops. Journal of Stress Physiology \& Biochemistry, 2019; 15 (4): 15-23

22. Jadhav RK., Dhurat H, Pawar T. Spectrophotometric analysis of deproteinised supernatant mediated silver nanoparticles synthesis obtained after leaf protein precipitation: The molecular approach World Journal Of Molecular Research. 2019; 2 (1): 1-10 